\title{
What are the scientific facts about the symptoms and treatment of COVID-19 in the pediatric population? A systematic review with overview
}

\author{
Quais são os fatos científicos sobre os sintomas e o tratamento de COVID-19 na população \\ pediátrica? Uma revisão sistemática com visão geral \\ ¿Cuáles son los datos científicos sobre los síntomas y el tratamiento del COVID-19 en la población \\ pediátrica? Una revisión sistemática con una visión general
}

Received: 07/18/2021 | Reviewed: 07/23/2021 | Accept: 07/28/2021 | Published: 08/04/2021

\author{
Vitória Monteiro Monte Oliveira \\ ORCID: https://orcid.org/0000-0002-4606-9367 \\ Ceará State University, Brazil \\ E-mail: vitoria.monte@aluno.uece.br \\ Paulo Francisco de Almeida-Neto \\ ORCID: https://orcid.org/0000-0002-2860-2260 \\ Federal University of Rio Grande do Norte, Brazil \\ E-mail: paulo.neto.095@ufrn.edu.br \\ Francisca Dalila Paiva Damasceno de Lima \\ ORCID: https://orcid.org/0000-0002-2415-9652 \\ Ceará State University, Brazil \\ E-mail: dalila.paiva@aluno.uece.br \\ Stefanny Karla Ferreira de Sousa \\ ORCID: https://orcid.org/0000-0001-5367-2714 \\ Ceará State University, Brazil \\ E-mail: stefanny.sousa@aluno.uece.br \\ André Carvalho de Sousa \\ ORCID: https://orcid.org/0000-0003-4109-1351 \\ Ceará State University, Brazil \\ E-mail: dre.carvalho@aluno.uece.br \\ Ruth Silva Galdino \\ ORCID: https://orcid.org/0000-0003-4936-8888 \\ Ceará State University, Brazil \\ E-mail: ruth.galdino@aluno.uece.br \\ Dihogo Gama de Matos \\ ORCID: https://orcid.org/0000-0002-7394-8527 \\ University of Manitoba, Winnipeg, Canada \\ Email: dematosd@myumanitoba.ca \\ Alexandre Bulhões-Correia \\ ORCID: https://orcid.org/0000-0002-9975-8625 \\ Federal University of Rio Grande do Norte, Brazil \\ E-mail: alexandre.bulhoes@ufrn.br \\ Breno Guilherme de Araújo Tinôco Cabral \\ ORCID: https://orcid.org/0000-0002-9966-9956 \\ Federal University of Rio Grande do Norte, Brazil \\ E-mail: brenotcabral@ reitoria.ufrn.br \\ Glaucia Posso Lima \\ ORCID: https://orcid.org/0000-0002-5000-2050 \\ Ceará State University, Brazil \\ E-mail: glaucia.posso@uece.br
}

\begin{abstract}
Considering the lower prevalence of pediatric patients with COVID-19, health professionals are more familiar with interventions aimed at adults; thus, understanding the symptoms and which approaches can be useful for pediatric patients with COVID-19 is of great importance for health professionals. The study aimed to aggregate scientific data on procedures and treatments performed on pediatric patients (aged 6 to 17 years) with COVID-19. A systematic literature search was performed in five electronic databases (i.e., PubMed, CINAHL, Google Scholar, and LILACS). Literature analyses were performed in English and Chinese, between November 2019 and December 2020. For data classification, the web application Rayyan ${ }^{\circledR}$ was used. Studies have shown that in most cases, children are asymptomatic. However, when symptomatic, they present fever, cough, intestinal infection, and vomiting. It is
\end{abstract}


noteworthy that the respiratory rate and stool tests were significant indicators of the disease. Regarding treatment, oxygen support is essential during the hospitalization of patients and, antiviral therapy with Lopinavir and Ritonavir has shown significant results in a few isolated cases. It is concluded that the main symptoms of SARS-CoV-2 in pediatric patients are mild symptoms similar to those of common flu. In addition, respiratory rate and examinations based on fecal samples are good indicators of the disease in children of both sexes, as well as antiviral therapies and early isolation at the beginning of the disease are significant for the healing process.

Keywords: Children; Adolescents; COVID-19; Systematic review.

\section{Resumo}

Considerando a menor prevalência de pacientes pediátricos com COVID-19, os profissionais de saúde estão mais familiarizados com as intervenções destinadas a adultos; assim, compreender os sintomas e quais condutas podem ser úteis para pacientes pediátricos com COVID-19 é importante para os profissionais de saúde. O estudo objetivou agregar dados científicos sobre procedimentos e tratamentos realizados em pacientes pediátricos (de 6 a 17 anos) com COVID-19. Uma busca sistemática da literatura foi realizada em cinco bases de dados eletrônicas (i.e., PubMed, CINAHL, Google Scholar e LILACS). As análises da literatura foram realizadas nos idiomas inglês e chinês, entre novembro de 2019 e dezembro de 2020. Para a classificação dos dados, foi utilizado o aplicativo web Rayyanß. Na maioria dos casos, as crianças são assintomáticas. Porém, quando sintomáticos, apresentam febre, tosse, infecção intestinal e vômitos. Vale ressaltar que a frequência respiratória e os exames de fezes foram indicadores significativos da doença. Em relação ao tratamento, o suporte de oxigênio é essencial durante a internação dos pacientes e, a terapia antiviral com Lopinavir e Ritonavir tem mostrado resultados significativos em casos isolados. Concluiu-se que os principais sintomas da SARS-CoV-2 em pacientes pediátricos são sintomas leves semelhantes aos da gripe comum. Além disso, a frequência respiratória e os exames com base em amostras fecais são bons indicadores da doença em crianças de ambos os sexos, assim como as terapias antivirais e o isolamento precoce no início da doença são importantes para o processo de cicatrização.

Palavras-chave: Crianças; Adolescentes; COVID-19; Revisão sistemática.

\section{Resumen}

Teniendo en cuenta la menor prevalencia de pacientes pediátricos con COVID-19, los profesionales de la salud están más familiarizados con las intervenciones dirigidas a adultos; por lo tanto, comprender los síntomas y qué enfoques pueden ser útiles para los pacientes pediátricos con COVID-19 es importante para los profesionales de la salud. El estudio tuvo como objetivo agregar datos científicos sobre procedimientos y tratamientos realizados en pacientes pediátricos (de 6 a 17 años) con COVID-19. Se realizó una búsqueda bibliográfica sistemática en cinco bases de datos electrónicas (es decir, PubMed, CINAHL, Google Scholar y LILACS). Los análisis de la literatura se realizaron en inglés y chino, entre noviembre de 2019 y diciembre de 2020. Para la clasificación de los datos se utilizó la aplicación web Rayyan®. En la mayoría de los casos, los niños son asintomáticos. Sin embargo, cuando son sintomáticos, presentan fiebre, tos, infección intestinal y vómitos. Es de destacar que la frecuencia respiratoria y las pruebas de heces fueron indicadores significativos de la enfermedad. En cuanto al tratamiento, el soporte de oxígeno es fundamental durante la hospitalización de los pacientes y la terapia antiviral con Lopinavir y Ritonavir ha mostrado resultados significativos en casos aislados. Se concluyó que los principales síntomas del SARS-CoV-2 en pacientes pediátricos son síntomas leves similares a los de la gripe. Además, la frecuencia respiratoria y los exámenes basados en muestras fecales son buenos indicadores de la enfermedad en niños de ambos sexos, así como las terapias antivirales y el aislamiento temprano al inicio de la enfermedad son importantes para el proceso de curación.

Palabras clave: Niños; Adolescentes; COVID-19; Revisión sistemática.

\section{Introduction}

In the province of Hubei located in the city of Wuhan in China, during the year 2019, there was the beginning of the outbreak of a respiratory infection caused by a new type of Coronavirus, popularly known as COVID-19 (Du et al, 2020). In that city, a total of 79,968 cases were confirmed, and due to the high transmission capacity of the new virus, this disease spread rapidly to all parts of the world (World Health Organization, 2020).

Thus, after several deaths and infections resulting from COVID-19 in the city of Wuhan, it was found, from respiratory samples from infected individuals, that this disease is caused by the Severe Acute Respiratory Syndrome Coronavirus 2 (SARS-CoV-2) (Zhou et al, 2020). In this sense, in March 2020, COVID-19 started to be qualified by the World Health Organization as a pandemic disease, which required the taking of preventive measures (i.e., distance and or social isolation) in the whole world society (Cucinotta, \& Vanelli, 2020; de Matos et al, 2020). 
Initially, the cases that drew the attention of the health authorities were concentrated in the adult population due to the greater number of people affected and the severity of the disease's progression, which is associated with the higher numbers of hospitalizations due to the disease ( $\mathrm{Du}$ et al, 2020). The clinical manifestations most commonly seen in those infected are fever, dry cough, sore throat, and tiredness (World Health Organization, 2020). Subsequently, other neurological symptoms such as anosmia (i.e., loss of smell) and ageusia (i.e., loss of taste) were associated, and gastrointestinal symptoms such as diarrhea (Guo et al, 2020).

However, concerning pediatric cases, lower rates of symptomatic progression and lower ratios of hospitalization for the disease were observed compared to the adult population (Wang \& Brar, 2020). In general, there was a lower prevalence in adults, which contributes to the relative scarcity of information regarding pediatric cases of COVID-19 (Hoang et al, 2020).

In this way, information about the particularities of COVID-19 in pediatric patients is necessary to aid medical interventions in this population; thus, the present study aimed to aggregate scientific data through a systematic review of cases of COVID-19 in pediatric patients.

\section{Methods}

\section{Study type and Study protocol record}

To ensure greater rigor to this scientific contribution the Systematic Review was adopted as a methodological tool, which is more rigorous and structured compared to other types of review (Aromataris \& Pearson, 2014). All the details for the management of this type of study followed the guidelines listed in the PRISMA protocol, as well as those of the Joanna Briggs Institute, reducing the risk of bias (Moher et al, 2015; Moola, 2015).

This research is a rapid systematic review with an overview with registration approved by the International Prospective Register of Systematic Reviews (PROSPERO, ID: CRD42020181835), guaranteeing authenticity, and originality to the study. The registration with PROSPERO is valid for work related to health, being important to avoid duplicate systematic reviews to ensure less risk of bias, and also to ensure a good methodological structuring and impartiality (Rombey, Doni, Hoffmann, Pieper \& Allers, 2020). In addition, a previous study by our group (Oliveira et al, 2021) made the protocol of this systematic review publicly available in open access, thus allowing for the transparency of the procedures carried out.

\section{Research methods for identifying studies}

For the design of the study, the "PID" method (population, intervention, and design) was used, mentioned in Tufanaru (Tufanaru, Munn, Aromataris, Campbell \& Hopp, 2017). In this study, the population was defined as pediatric, while intervention and design remained unfiltered. The studies were searched in four databases (PubMed, Google Scholar, LILACS, and CINAHL), using the date (November 2019 to December 2020) and the language (English and Chinese) as a filter. During searches, the descriptors registered in MesSH "Child, Children and COVID-19" were used, combined with the Boolean operators "OR" and "AND"; Research methods for identifying studies.

\section{Inclusion criteria}

Scientific texts that addressed the theme of COVID-19 concerning pediatric patients aged 6 to 17 years were included. The study designs considered were: clinical trials, observational, literature review, systematic review, and brief communications. 


\section{Data management}

Rayyan ${ }^{\circledR}($ Qatar Computing Research Institute, Qatar) was used as a tool for data management, whose functionality in this study consists of storing the selected articles in the databases, through importation, and then filtering them. Through this tool, it is possible to check the level of agreement between researchers and, based on their decisions, include or exclude articles (Ouzzani, Hammady, Fedorowicz \& Elmagarmid, 2016).

\section{Classification and data extraction.}

The search stage was carried out by three researchers, individually and with a blind assessment. This process was organized into the sub-stages: (i) Selection by title and import in Rayyan ${ }^{\circledR}$; (ii) Individual reading of the abstracts of articles directly in Rayyan ${ }^{\circledR}$ for inclusion or exclusion, with conflicts resolved by an external researcher; (iii) Reading the studies in full, to see which ones fit the criteria, and in cases of disagreement, there was the presence of a researcher not involved in the search stage.

\section{Bias Analysis}

To analyze the methodological quality of the articles classified in (i) Systematic review, (ii) Literature review, (iii) Brief communication, and (iv) Short communication, the Overview Quality Assessment Questionnaire (OQAQ) was used, which offers a score of 1 to 9 for each study, classifying studies $<4$ as weak and strong those evaluated with a score $>5$ (Oxman \& Guyatt, 1991). Observational studies were analyzed using the Loney quality scale, which makes it possible to classify the quality of the work structure, which can be defined as "high risk," "low risk," or "uncertain risk" (Loney, Chambers, Bennett, Roberts \& Stratford, 1998). The entire analysis process focused on the methodological bias, results, reproducibility, quality of evidence, and blinding of the observational study (Loney, Chambers, Bennett, Roberts e Stratford, 1998). The entire bias analysis process was carried out individually, in a blind assessment, by a team of three researchers, who, after completing the stage, communicated to a fourth researcher, who was responsible for removing the blinding, analyzing agreement, and extracting the result end of the process.

\section{Summary of quantitative data}

The agreement of the bias analysis between the study researchers was verified by the Interclass Correlation Coefficient (ICC) (for data on the OQAQ scale) and the Kappa coefficient (for data on the Loney scales) (Oxman \& Guyatt, 1991; Loney, Chambers, Bennett, Roberts \& Stratford, 1998; Miot, 2016). The magnitude adopted was: absence: ICC or Kappa $=\leq 0$; poor: ICC or Kappa $=0-0.19$; weak: ICC or Kappa $=0.20-0.39$; moderate: ICC or Kappa $=0.30-0.59$; substantial: ICC or Kappa $=0.60-0.79$; and almost complete: $\mathrm{ICC}$ or Kappa $=\geq 0.80$ (Miot, 2016). The heterogeneity of the studies was analyzed using Cochran's $Q$ and $I^{2}$ statistics. The studies were considered heterogeneous when: $\mathrm{I}^{2}>50 \%$ and significance level $<0.05$ (Dinnes, Deeks, Kirby \& Roderick, 2005). All analyses were performed using the open-source R software (Version 4.0.1, Foundation for Statistical Computing ${ }^{\circledR}$, Vienna, Austria), which the significance level considered will be $\mathrm{p}<0.05$.

\section{Summary of qualitative data}

The analysis of qualitative data was carried out by creating tables with the main features of each article included in this review. When suitable, eligibility figures and procedures were also used to expose the quality of the evidence found (Egger, Smith, Phillips, 1997). 


\section{Results}

Figure 1. Flowchart of identification and selection of articles for systematic review.
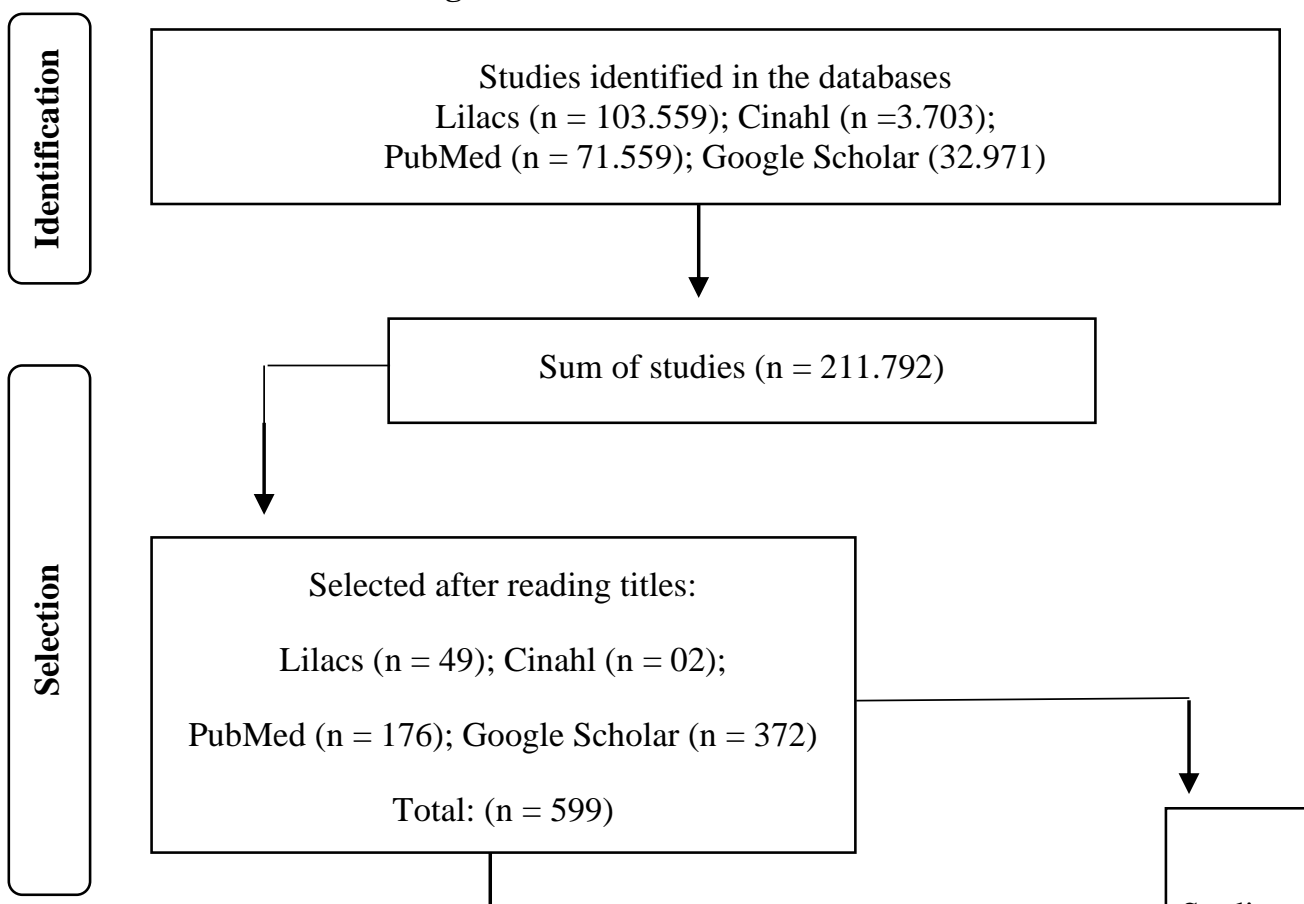

Lilacs $(\mathrm{n}=49)$; Cinahl $(\mathrm{n}=02)$;

PubMed $(n=176) ;$ Google Scholar $(n=372)$

Total: $(\mathrm{n}=599)$

Studies selected for full reading after reading abstracts $(n=139)$

\section{Studies excluded after reading in full:}

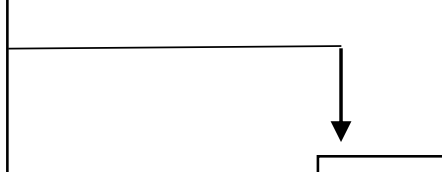

Studies excluded after reading abstracts:

- Non-focused approach to health $(n=60)$

- Inadequate sample $(n=148)$

- Patient with multiple diseases $(n=15)$

- Inadequate study design $(\mathrm{n}=57)$

- Incomplete text $(\mathrm{n}=84)$

- Studies outside research time $(\mathrm{n}=94)$

- $\quad$ Not having access to the full text $(n=10)$

- Not meeting the inclusion criteria of the study $(n=60)$

- $\quad$ Not consistent with the theme of the present study $(n=49)$

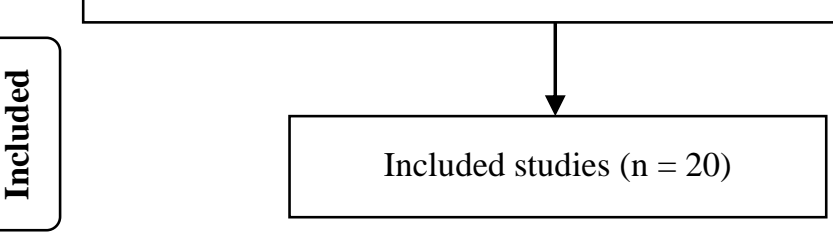

Source: Authors.

Figure 1 shows the flowchart of the general outline of this study concerning the identification and selection of the articles included in this systematic review. The flowchart shows the total number of articles found, the number included and excluded, and the reason for the exclusion. 
Table 1. Characteristics of studies grouped by the review.

\begin{tabular}{lcl}
\hline $\begin{array}{c}\text { Studies } \\
\text { (Authors) }\end{array}$ & Sample & \multicolumn{1}{c}{ Methodology } \\
& & \\
& -9 children $(1$ to 12 years & - Retrospective study. \\
Shen et al & old, unidentified sex $).$ & - Epidemiological and clinical data \\
$(2020)$. & & $\begin{array}{l}\text { were analyzed concerning the } \\
\text { sample analyzed. }\end{array}$
\end{tabular}

Park, Han, - a 10 year old female Park, Kim \& Child Choi (2020).
Su et al

(2020).

\section{Case study}

Nasopharynx, throat, saliva, serum, feces and urine tests, and chest ct scan were performed.
- Retrospective study.

- Analysis of clinical conditions, laboratory, and radiological exams.
- Oxygen support was provided to patients.

- Antiviral therapy was performed with lopinavir and ritonavir.

- Symptoms such as fever, cough, sore throat, and diarrhea have been shown alone or in combination.

The child was asymptomatic until the 13th day after the infection.

Small amount of sputum was the only symptom. In addition, nodules were found in subpleural areas of the right lower pulmonary lobe.

Only the stool test result remained positive until the 17 th day after the onset of symptoms.

- Both children show positive results in the detection of nucleic acids. months to 9 years (unidentified sex).

- fever was the only symptom detected.

- a patient had bronchitis; however, he did not show respiratory symptoms.

Children $>5$ years of age had polypnea $\quad(\geq 30$ times/min).

- Children aged $<2 \quad$ - Review article.

Shen \& Yang et al (2020). months and $>5$ years.
- Scientific articles that addressed the diagnosis and treatment of covid-19 in children were included.
- Increased respiratory weakness was indicated as an early warning by covid-19 ( $\geq 30$ times/min for children older than five years).

- Review article.

Children of both sexes, aged between 07 and 13 years.
- Scientific articles addressing symptoms of covid-19 in children were included.
- The children had mild symptoms such as fever and cough.

- Most of the children had radiographic changes in the chest.

Retrospective study.

Subjects who reported two of the following symptoms were included: symptoms of upper respiratory infection (uri), gastrointestinal symptoms (gi), and fatigue.

Stratification of patients according to severity, mild, moderate, severe, and critical.

\section{Patients with mild} severity had a runny nose, fever, cough, fatigue, sneezing, sore throat, pneumonia. Those of moderate severity had severe respiratory symptoms.

- $\quad$ Critically ill patients had acute respiratory distress syndrome or other organ dysfunction.

\section{Both}

gastrointestinal symptoms, such as abdominal pain, nausea, vomiting, and diarrhea.

- the symptom found was mild - brief report.

- male children, nine years Ji et al (2020). old.
- retrospective analysis of two pediatric cases confirmed with covid19. diarrhea for 2 days with no fever.

- no abnormalities were observed in leukocytes, protein c, and chest
Conclusions

The symptoms of covid-19 in children were atypical, showing less aggression to the body in relation to the symptoms identified in other age groups.

The study could not reach conclusive results due to the lack of studies involving children. However, the study indicates that the analyzed child showed limited symptoms in relation to covid-19.

Pediatric patients should be cared for in an environment isolated from other family members, and care should be taken from the initial symptoms.

Respiratory weakness may be a significant indicator of covid-19 in pediatric patients aged $>5$ years.

Children appear to be protected from the manifestation of the severe form of the disease, and discontinuation of treatment can be harmful, resulting in crises of the disease.

Gastrointestinal symptoms are present in patients with different levels of disease severity. Patients with mild severity had symptoms similar to a common viral disease, while patients with critical severity have respiratory problems.

There are mild symptoms in pediatric patients with covid19 , which makes it difficult to diagnose the disease. 
- investigation of epidemiological characteristics, clinical examinations, laboratory studies, and clinical results were described.

Ma et al 9 years

(2020).

- female children, aged 8 to

- short communication.

- use of an analysis kit using the pcr method for testing feces. computed tomography.

- positive respiratory samples in patients, and negative for feces in the 1 st week.

- patients had a positive stool test four weeks after the onset of symptoms.

- show positive results in the stool after discharge.

- male children, aged 6 to 9 children diagnosed with covid-19,

Zhang et al years.

(2020).

- female children, six years old.

Xing et al (2020).

Chiotos

- children of both sexes et al (2020).
- short communication.

- analyzed information collected from such as clinical characteristics, laboratory tests, chest images, and etiological examination.

-review article.

-analysis of epidemiological, clinical,

-after discharge due to recovery from light contamination, samples of sars-cov-2 were observed in the feces of pediatric patients within ten days.

-sars-cov-2 fragments were seen in stool tests after four weeks after low fever, and the elimination of viral rna occurred in two weeks in the throat smear.

-monitoring the results of the smear exams of the throat and feces.

\section{-case report.}

-analyzed clinical, laboratory, and therapeutic characteristics of a group of children.

- the main symptoms found were, mainly, diarrhea, fever, shock, variable presence of skin rash, edema in the extremities and -review article.

-to better understand the characteristics of covid-19, the study

- children infected with was based on experiences learned Zhou et al covid-19.

(2020).

from sars, data, and terms of clinical aspects and pathogenesis. -were selected studies that had information about children infected with covid-19.

- observational study.

- children of both sexes between 6 and 12 years Zhu et al old. (2020).

Mcabee,

Brosgol,

- 1 male child, 11 years

Pavlakis, Agha

\& Gaffoor

(2020).

Lou, Shi, Zhou 8 years.

\& Tian (2020). -collected clinical, epidemiological, and demographic information in children's medical records after their selection in various hospitals.

- correspondence article

-reported the clinical condition of a child with covid-19 and its recovery process.

\section{-brief communication.}

-reported characteristics of children affected by covid- 19 . changes in the mucous membrane, conjunctivitis, abdominal pain, respiratory failure, and vomiting.

- covid-19 transmissibility was superior to sars; spread by children is present in covid-19, unlike sars, in which it has not been reported.

- clinical spectrum: the incubation period was practically the same, while sars is 2-14 days; covid-19 is 1-14 days.

- no patient had leukopenia and lymphopenia at entry.

- pneumonia was seen on chest ct images in some patients.

- an antiviral treatment was performed in 5 patients.

- the child had a two-day history of weakness without symptoms related to the respiratory system or fever.

- electroencephalography showed intermittent frontal delta activity.

- all children had high temperatures. None had dyspnea or cyanosis.

-two patients had nasal congestion and rhinitis, associated with fatigue, diarrhea, and headache.

-the child received medicines of chinese origin, antipyretic, against malaise and strengthening of the body, and inhalation of interferon against viruses.

-after the treatment, the nucleic acid in the respiratory system
Sars-cov- 2 can be eliminated in the fecal remains of some patients in the recovery phase.

Recovered patients may be possible transmitters of covid19 through feces, requiring re-evaluation of hospital discharge criteria.

Sars-cov-2 remains for less time in the respiratory system than in the gastrointestinal system in pediatric patients.

More epidemiological and clinical data are needed to measure the prevalence of this condition, observing the relationship with infections by sars-cov- 2 .

Data on children with covid19 is limited. It is also urgent, especially in poor countries without pediatric data, to define the severity of the disease and the clinical characteristics.

Children infected with covid19 had less severe symptoms and better treatment results.

screening of children with encephalitis due to sars-cov-2 infection was recommended, as these patients require greater care.

Few cases have been reported about children infected with sars-cov-2. Treatment in the early stage of the disease contributed to faster recovery.

Drug monitoring is necessary to increase the effectiveness, safety of child medication, and rationality while improving medication adherence. 


\begin{tabular}{|c|c|c|c|c|}
\hline & & & samples became negative. & \\
\hline $\begin{array}{c}\text { Mehta } \\
\text { et al }(2020) \text {. }\end{array}$ & $\begin{array}{l}\text { - studies on covid-19 in } \\
\text { pediatric patients. }\end{array}$ & $\begin{array}{l}\text { - a systematic review (meta-analysis). } \\
\text { - a quick, systematic review was } \\
\text { carried out, with the collection of all } \\
\text { literature with pediatric populations } \\
\text { linked to covid- } 19 \text {. }\end{array}$ & $\begin{array}{l}\text { - limited data show that children } \\
\text { are equally susceptible to the } \\
\text { disease. } \\
\text { - reports of asymptomatic } \\
\text { infection and milder development } \\
\text { of the disease in children. } \\
\text { However, radiological } \\
\text { abnormalities have been found. }\end{array}$ & $\begin{array}{l}\text { Children appear to be less } \\
\text { affected by sars-cov- } 2 \\
\text { infections. However, this } \\
\text { observation can be misleading } \\
\text { due to a large number of } \\
\text { asymptomatic patients. }\end{array}$ \\
\hline $\begin{array}{l}\text { Ludvigsson et } \\
\text { al }(2020) \text {. }\end{array}$ & $\begin{array}{l}\text { - children of both sexes } \\
\text { with a median age of } 6-7 \\
\text { years. }\end{array}$ & $\begin{array}{l}\text { - a systematic review. } \\
\text { - they sought to identify studies } \\
\text { published between january and march } \\
2020 \text { with the theme covid-19 in } \\
\text { children. }\end{array}$ & $\begin{array}{l}\text { - children accounted for } 1 \% \text { to } \\
5 \% \text { of diagnosed covid- } 19 \text { cases. } \\
\text { - children have milder illnesses } \\
\text { than adults, and deaths have been } \\
\text { extremely rare. } \\
\text { - the symptoms mentioned are } \\
\text { fever and mild respiratory } \\
\text { symptoms. }\end{array}$ & $\begin{array}{l}\text { Covid-19 disease occurred in } \\
\text { children but appeared to have } \\
\text { a milder disease course and } \\
\text { better prognosis than adults. } \\
\text { Deaths were rare. }\end{array}$ \\
\hline $\begin{array}{l}\text { Lan et al } \\
(2020) \text {. }\end{array}$ & $\begin{array}{l}\text { - four children (a 7-year- } \\
\text { old boy, a 7-year-old girl, a } \\
\text { 12-year-old boy, and a 13- } \\
\text { year-old girl). }\end{array}$ & $\begin{array}{l}\text { - observational study. } \\
\text { - patients undergoing computed } \\
\text { tomography (ct). } \\
\text { - data on clinical and computed } \\
\text { tomographic characteristics were } \\
\text { collected and analyzed. }\end{array}$ & $\begin{array}{l}\text { - patients were asymptomatic } \\
\text { throughout the course of the } \\
\text { disease (ranging from } 7 \text { to } 15 \\
\text { days), and none of them had } \\
\text { abnormalities in blood cell } \\
\text { counts. } \\
\text { - thin-section ct revealed } \\
\text { abnormalities in three patients. } \\
\text { - unilateral lung involvement was } \\
\text { seen in two patients, and one } \\
\text { patient had bilateral lung } \\
\text { involvement. }\end{array}$ & $\begin{array}{l}\text { Small patches of ground-glass } \\
\text { opacity with subpleural } \\
\text { distribution and unilateral } \\
\text { lung involvement were } \\
\text { common findings on ct scans } \\
\text { of early-stage pediatric } \\
\text { patients. }\end{array}$ \\
\hline $\begin{array}{l}\text { Zhu et al } \\
(2020) \text {. }\end{array}$ & $\begin{array}{l}\text { - children of both sexes } \\
\text { aged between } 9 \text { and } 17 \\
\text { years old. }\end{array}$ & $\begin{array}{l}\text { - observational study. } \\
\text { - demographic, epidemiological, and } \\
\text { clinical data were collected from } \\
\text { medical records. } \\
\text { - all patients were confirmed by real- } \\
\text { time quantitative reverse } \\
\text { transcriptase-polymerase chain } \\
\text { reaction (rt-pcr) method in throat } \\
\text { swab specimen or anal swab } \\
\text { specimen. }\end{array}$ & $\begin{array}{l}\text { - seven patients had contact with } \\
\text { family members diagnosed with } \\
\text { covid- } 19 \text { before disease onset. } \\
\text { - common symptoms were fever } \\
\text { ( } 40 \% \text { of patients) and cough }(30 \% \\
\text { of patients). } \\
\text { - pneumonia was seen on chest ct } \\
\text { images in } 50 \% \text { of patients. }\end{array}$ & $\begin{array}{l}\text { Children with covid-19 have } \\
\text { less severe symptoms and } \\
\text { have better results in treating } \\
\text { the disease. }\end{array}$ \\
\hline
\end{tabular}

Source: Authors.

The studies shown in Table 1 indicated that the scientific facts about the symptoms and treatment of COVID-19 in the pediatric population are still inconsistent. In most cases, children remain asymptomatic, which makes it difficult to diagnose the disease. However, from the included studies, seven demonstrated that the main symptoms in pediatric patients are fever and cough, one identified that sore throat is a secondary symptom, and four showed that gastrointestinal symptoms such as intestinal infection and vomiting are also associated with infected pediatric patients by COVID-19.

In addition, four articles showed that after discharge from the hospital, patients continue to eliminate fragments of SARS-CoV-2 through the stool. One study demonstrated the effectiveness of antiviral therapy with Lopinavir and Ritonavir. Six authors identified through computed tomography that the disease slightly affects the respiratory system of pediatric patients. One study identified that patients at serious risk point to respiratory symptoms that require more attention during treatment and, one study showed that respiratory weakness can be a significant indicator for the early detection of COVID-19 contamination.

When considering all studies grouped, the heterogeneity between the studies was $\mathrm{I}^{2}>40 \%$ and, the scientific texts gathered were not compatible with carrying out a meta-analysis. 
Table 2. Analysis of bias in bibliographic studies using the OQAQ scale and agreement index between the evaluators involved in the analyses.

\begin{tabular}{lcc}
\hline \multicolumn{1}{c}{ Studies (Authors) } & OQAQ Score & ICC \\
\hline Shen et al (2020). & 3 & 0.70 \\
Hedrich (2020). & 4 & 0.53 \\
Zhou et al (2020). & 3 & 0.73 \\
Mehta et al (2020). & 4 & 0.61 \\
Ma et al (2020). & 3 & 0.51 \\
Zhang et al (2020). & 2 & 0.44 \\
McAbee, Brosgol, Pavlakis, Agha \& Gaffoor (2020). & 2 & 0.49 \\
Lou, Shi, Zhou \& Tian (2020). & 2 & 0.70 \\
Ludvigsson et al (2020). & 4 & 0.95 \\
\hline
\end{tabular}

OQAQ = Overview Quality Assessment Questionnaire for review studies (increasing scale from 1 to 9). ICC = Intraclass Correlation Coefficient between the evaluators in relation to the bias analysis scores by the OQAQ. ICC magnitude: absence: $\mathrm{ICC}=\leq 0$; poor: $\mathrm{ICC}=0-0.19$; weak: $\mathrm{ICC}=0.20-0.39$; moderate: ICC = 0.30-0.59; substantial: ICC $=0.60-0.79$; and almost complete: $\mathrm{ICC}=\geq 0.80$.

Source: Authors.

The bias analysis of the eight review studies showed scores of weak magnitude, suggesting that the studies have significant methodological weaknesses. It should be noted that the degree of agreement between the evaluators involved in the bias analysis was positive, with magnitudes that varied between moderate (ICC: 0.30-0.59) to substantial (ICC: 0.60-0.79) and almost complete (ICC>0.80), as presented in Table 2. 
Table 3. Analysis of biases in observational studies using the Loney scale and agreement index between the evaluators involved in the analyses.

\begin{tabular}{|c|c|c|c|c|c|c|c|c|}
\hline Studies (Authors) & Bias 1 & Kappa 1 & Bias 2 & Kappa 2 & Bias 3 & Kappa 3 & Bias 4 & Kappa 4 \\
\hline Shen \& Yang et al (2020) & $\downarrow$ & 0.78 & $\uparrow$ & 0.68 & $\downarrow$ & 0.70 & $\downarrow$ & 0.80 \\
\hline Park, Han, Park, Kim e Choi (2020) & $\uparrow$ & 0.76 & $\uparrow$ & 0.66 & $\uparrow$ & 0.67 & $\downarrow$ & 0.82 \\
\hline Su et al (2020). & $\downarrow$ & 0.69 & $\uparrow$ & 0.60 & $\downarrow$ & 0.71 & $\downarrow$ & 0.75 \\
\hline Xing et al (2020). & $\downarrow$ & 0.81 & $\uparrow$ & 0.69 & $\downarrow$ & 0.70 & $\downarrow$ & 0.72 \\
\hline Chiotos et al (2020). & $\downarrow$ & 0.72 & / & 0.58 & $\downarrow$ & 0.66 & $\downarrow$ & 0.65 \\
\hline Zhu et al (2020). & $\downarrow$ & 0.71 & $\uparrow$ & 0.67 & $\uparrow$ & 0.71 & $\downarrow$ & 0.60 \\
\hline Wang e Brar (2020) & $\downarrow$ & 0.70 & / & 0.57 & $\downarrow$ & 0.65 & $\downarrow$ & 0.55 \\
\hline Shang et al (2020). & $\downarrow$ & 0.77 & $\downarrow$ & 0.55 & $\uparrow$ & 0.70 & $\downarrow$ & 0.70 \\
\hline Ji et al (2020). & $\downarrow$ & 0.82 & $\uparrow$ & 0.62 & $\uparrow$ & 0.69 & $\downarrow$ & 0.73 \\
\hline Zhu et al (2020). & / & 0.95 & $\uparrow$ & 0.92 & $\downarrow$ & 0.90 & $\downarrow$ & 0.97 \\
\hline \multirow[t]{2}{*}{ Lan et al (2020). } & $\downarrow$ & 0.80 & 1 & 0.73 & $\downarrow$ & 0.84 & $\downarrow$ & 0.90 \\
\hline & Bias 5 & Kappa 5 & Bias 6 & Kappa 6 & Bias 7 & Kappa 7 & $\begin{array}{ll}--- \\
\end{array}$ & ---- \\
\hline Shen \& Yang et al (2020) & / & 0.59 & $\downarrow$ & 0.75 & $\downarrow$ & 0.80 & $\begin{array}{ll}--- \\
-\cdots\end{array}$ & $\begin{array}{ll}--- \\
-\cdots\end{array}$ \\
\hline Park, Han, Park, Kim e Choi (2020) & $\uparrow$ & 0.42 & $\downarrow$ & 0.70 & $\downarrow$ & 0.77 & --- & --- \\
\hline Su et al (2020). & / & 0.61 & $\downarrow$ & 0.70 & $\downarrow$ & 0.70 & --- & --- \\
\hline Xing et al (2020). & / & 0.69 & $\downarrow$ & 0.71 & $\downarrow$ & 0.82 & --- & --- \\
\hline Chiotos et al (2020). & $\uparrow$ & 0.62 & $\uparrow$ & 0.80 & $\downarrow$ & 0.66 & --- & --- \\
\hline Zhu et al (2020). & / & 0.55 & $\uparrow$ & 0.76 & $\downarrow$ & 0.70 & --- & --- \\
\hline Wang e Brar (2020). & $\uparrow$ & 0.60 & $\downarrow$ & 0.71 & $\downarrow$ & 0.68 & --- & --- \\
\hline Shang et al (2020). & $\uparrow$ & 0.70 & $\downarrow$ & 0.65 & $\downarrow$ & 0.75 & --- & --- \\
\hline Ji et al (2020). & I & 0.54 & $\uparrow$ & 0.60 & / & 0.61 & --- & --- \\
\hline Zhu et al (2020). & $\uparrow$ & 0.90 & $\uparrow$ & 0.91 & $\uparrow$ & 0.88 & --- & --- \\
\hline Lan et al (2020). & / & 0.63 & $\downarrow$ & 0.82 & $\uparrow$ & 0.98 & & \\
\hline
\end{tabular}

$\downarrow=$ Low risk. $\uparrow=$ High risk. $/=$ Uncertain risk.

Kappa = Index of agreement between the evaluators regarding the analysis of biases for each type of bias on the Loney scale (1998). Kappa magnitude: absence: Kappa $=\leq 0$; poor: Kappa $=0-0.19$; weak: Kappa $=0.20-0.39$; moderate: Kappa $=0.30-0.59$; substantial: Kappa $=0.60-0.79$; and almost complete Kappa $=\geq 0.80$.

Bias $1=$ The study does not answer the research question adequately;

Bias $2=$ The sample base and the sample size were not adequate;

Bias 3 = Adequate and standardized objective criteria were not used for the outcome;

Bias $4=$ The result was measured in a biased way;

Bias $5=$ Results are not provided with a confidence interval when appropriate;

Bias $6=$ The study does not expose practical applicability;

Bias $7=$ The study is not reproducible for other samples from different populations.

Source: Authors.

Concerning the nine observational studies, nine studies present low risks for biases related to the answer to the research problem. Seven studies indicate high risks for sample-based biases. Seven studies showed low risks for outcome bias. All indicate low risks for outcome bias. Six studies demonstrated uncertain risks regarding the use of confidence intervals in the presentation of data. Seven studies were classified with low risk concerning practical applicability, and eight of the studies indicated low bias about reproducibility, according to Table 3.

\section{Discussion}

The study aimed to conduct a rapid systematic review with an overview of the scientific facts regarding the symptoms, and treatment of the pediatric population concerning COVID-19. Thus, the main results were: (1) In most cases, children remain asymptomatic, which makes it difficult to diagnose the disease. (2) The main symptoms in pediatric patients are fever and cough, and the secondary symptoms are sore throat and gastrointestinal symptoms. (3) Patients at serious risk have mild respiratory symptoms, which can be identified by tomography or chest X-ray. (4) Antiviral therapy with Lopinavir and Ritonavir has indicated positive treatment results. (5) Respiratory weakness can be a significant indicator for the early detection of COVID-19 contamination. (6) After discharge from the hospital, patients continue to eliminate fragments of 
SARS-CoV-2 through the stool. (7) Analysis of biases in the review studies indicated scores of weak magnitude, suggesting that the studies have significant methodological weaknesses. (8) Most observational studies demonstrate low risks for biases related to research problems, results, practical applicability, and reproducibility. In addition, high risks for bias to the sample and uncertain risks concerning the use of the confidence intervals of the findings were also reported.

In this sense, we highlight that the topic of results demonstrates that in most cases, children infected with COVID-19 remained asymptomatic, making it difficult to diagnose the disease (McAbee, Brosgol, Pavlakis, Agha \& Gaffoor, 2020; Mehta et al, 2020). In this sense, according to Qiu et al (2020), about a third of the patients in a study with 36 participants did not present symptoms, and a fifth presented only pneumonia; thus, more tests were requested to be possible to diagnose the disease, among they did the radiography exam. In this examination, the findings showed two types of presentations, multiple and irregular opacities. However, according to Dhochak, Singhal, Kabra and Lodha (2020), one of the possible explanations for this strong immune barrier against the virus in children, either because they have more effective immune responses (innate and acquired), leaving them asymptomatic; consequently, causing some difficulties in identifying SARS-CoV-2.

Regarding the main pediatric symptoms presented, fever and cough are first and, the secondary ones are sore throat and gastrointestinal symptoms (Wang \& Brar, 2020; Shen et al, 2020; Su et al, 2020; Hedrich, 2020; Chiotos, 2020; Lou, Shi, Zhou \& Tian, 2020). According to Nunes et al (2020), the main clinical findings of COVID-19 in pediatric patients were fever and cough, followed by diarrhea, nausea, vomiting, and sore throat. The least common were headaches, dyspnoea, and nasal congestion. Ho, Oligbu, Ojubolamo, Pervaiz and Oligbu G (2020), in their study with 820 pediatric patients, demonstrated that fever and cough are the most frequent symptoms of symptomatic patients.

When observing the imaging aspects related to COVID-19's mild respiratory symptoms, the authors' Zhu et al (2020) observed that three out of ten patients in the cases had coughing. In addition, five patients (50\%) underwent typical examinations of chest computed tomography images. It is noteworthy that, this exam alone cannot be used to identify COVID19, and it is not done in asymptomatic cases; thus, three of the ten patients underwent COVID-19 screening after admission to verify their complaints and symptoms, in detail, to be properly diagnosed. Among the five patients, two showed bilateral ground-glass opacity and one in unilateral ground-glass. The authors Hedrich (2020) and Lou, Shi, Zhou e Tian (2020) verified in their studies children with COVID-19 in critical condition, who underwent chest radiographs. Unlike clinical cases in adults or critical elderly people, children did not demonstrate continuous or prolonged clinical or laboratory signs of syndromes (i.e., allergic attacks, dyspnoea, cyanosis, and others); thus, few children needed care or mechanical ventilation.

The topic of results showed that a study demonstrated that the drugs Lopinavir and Ritonavir indicated positive results in the treatment of COVID-19 in pediatric patients (Shen et al, 2020). According to Bonifácio, Faria and Sousa Júnior (2020) the effectiveness of treatment with the aforementioned drugs is inconclusive, since there are no clear benefits. Götzinger et al (2020) state that the opinions on the use of Lopinavir-ritonavir are divided, considering recent studies that have not reached conclusive results regarding the use of the drug for the treatment of COVID-19. In this line of thought, it becomes valid to state that the medications may not be the most suitable for the treatment of COVID-19, but it helps reasonably in some cases occasionally, and randomly.

At this point, it can be noted that respiratory weakness is a factor that may indicate the early detection of SARS-CoV2 , given that it is observed in several clinical signs in the performance of the anamnesis, as well as clinical symptoms reported by patients as abdominal pain, congestion in the pharynx, runny nose, sneezing, cough, and dyspnoea. All of these "common" respiratory symptoms are easily confused with everyday pathologies, such as the flu or allergies, probably due to a failed anamnesis; constantly, leading to inaccurate diagnoses. With a more focused screening on COVID-19, we will have the reduction of clinical errors and the adequate diagnosis in which these symptoms will lead to the appropriate classification, be it asymptomatic, mild, moderate, severe, or critical, consequently reducing the spread of the virus (Shen et al, 2020). 
Other results indicate that pediatric patients continue to eliminate fragments of SARS-CoV-2 in the feces after hospital discharge (Park, Han, Park, Kim \& Choi, 2020; Ma, 2020; Zhang, 2020; Xing et al, 2020). According to Tian, Rong, Nian and He (2020), the virus enters the gastrointestinal cells, and, in this way, the feces become potentially infectious; therefore, the recommendation of more thorough hygiene is indicated, in addition to isolation of 14 days after the high.

However, in the findings of Tian, Rong, Nian e He (2020), there were some limitations due to the sample size being small, so there is a need for proof with a larger number of samples. The low number of tests in many hospitals and clinics is due to the lack of materials for collection promptly for the pediatric population, in addition to the disparity of information from clinical conditions, and the lack of specific treatment protocols, only sometimes therapies were adopted differentiated. Several clinical cases have shown that some pediatric cases of COVID-19 were initially asymptomatic, or with few differentiating symptoms, which hindered the correct diagnosis. Some of the clinical outcomes were not performed on the date the study was conducted, so these limitations bring significant methodological weaknesses to the interpretation of data from the studies included in this review (Zhou et al, 2020; Shen et al, 2020; Hedrich, 2020; Ma, 2020; Zhang, 2020; McAbee, Brosgol, Pavlakis, Agha \& Gaffoor, 2020; Shang et al, 2020, Mehta et al, 2020).

We emphasize that the present study identified in the speech of authors such as Shen and Yang et al (2020), Park, Han, Park, Kim and Choi (2020), Su et al (2020), Xing et al (2020), and Chiotos et al (2020), that the sample used is small, and that they deal directly with ethical guidelines to develop their studies. Few scientific works/action protocols or intervention planning have been validated for large-scale treatments; thus, it is clear that there are problems for the development of their studies, which directly reflects on the research problem, of the result, practical applicability, and reproducibility.

However, the present study has the following limitations: The set of descriptors used in the methodology has a limited scope, and Despite the relevance, the databases used may not have been enough for the collection of studies available on the subject. However, this review brings together significant data that can be useful for clinical decision-making concerning the conduct to be taken for the treatment of pediatric patients with COVID-19.

\section{Conclusion}

It is concluded that the main symptoms of SARS-CoV-2 in pediatric patients are mild symptoms similar to those of common flu, which makes it difficult to identify the disease in this population. In addition, respiratory rate and examinations based on fecal samples are good indicators of the disease in children of both sexes, as well as antiviral therapies and early isolation at the beginning of the disease are significant for the healing process. However, it is emphasized that the scientific facts present in the literature are still inconsistent about the singularity of the symptoms and treatment of SARS-CoV-2 in pediatric patients. Therefore, it is recommended that more studies are conducted on this theme, related to the pediatric public.

\section{Acknowledgments}

For your support and encouragement for the development of this academic article, we thank the State University of Ceará (UECE), the Federal University of Rio Grande do Norte (UFRN), the Physical Activity and Health (AFISA) research base, the Child and Adolescent Maturation Research Group (GEPMAC), the Interprofessional Center for Chronic Diseases (NIDOC). The National Council for Scientific Development (CNPQ) and the Higher Education Personnel Improvement Coordination (CAPES).

\section{References}

Aromataris, E., \& Pearson, A. (2014). The systematic review: an overview. AJN The American Journal of Nursing, 114(3), 53-58. 
Bonifacio, K. F., Faria, S. K. S. D. C., \& Souza Jr., A. S. D. (2020). Drugs used in the treatment of COVID-19 in pediatrics: an integrative review. Comun ciênc saúde. 31 (Suplemento 1), 94-104.

Chiotos, K, Bassiri, H, Behrens, E. M, Blatz, A. M, Chang, J, Diorio, C, \& John, A. R. O (2020). Multisystem inflammatory syndrome in children during the coronavirus 2019 pandemic: a case series. Journal of the Pediatric Infectious Diseases Society, 9(3), 393-398.

Cucinotta, D, \& Vanelli, M (2020). WHO declares COVID-19 a pandemic. Acta Bio Medica: Atenei Parmensis, $91(1), 157$.

De Matos, D. G, Aidar, F. J, Almeida-Neto, P. F, Moreira, O. C, Souza, R. F D, Marçal, A. C \& Guerra, I (2020). The impact of measures recommended by the government to limit the spread of coronavirus (COVID-19) on physical activity levels, quality of life, and mental health of Brazilians. Sustainability, 12(21), 9072.

Dhochak, N, Singhal, T, Kabra, S. K, \& Lodha, R (2020). Pathophysiology of COVID-19: why children fare better than adults?. Indian journal of pediatrics, 1 .

Dinnes, J., Deeks, J., Kirby, J., \& Roderick, P (2005). A methodological review of how heterogeneity has been examined in systematic reviews of diagnostic test accuracy. Health technology assessment (Winchester, England), 9(12), 1-113.

Du, Z, Wang, L, Cauchemez, S, Xu, X, Wang, X, Cowling, B. J, \& Meyers, LA (2020). Risk for transportation of coronavirus disease from Wuhan to other cities in China. Emerging infectious diseases, 26(5), 1049.

Egger, M, Smith, G. D, \& Phillips, A. N (1997). Meta-analysis: principles and procedures. Bmj; 315(7121), $1533-1537$.

Götzinger, F, Santiago-García, B, Noguera-Julián, A, Lanaspa, M, Lancella, L, Carducci, F. I. C, \& Riordan, A (2020). COVID-19 in children and adolescents in Europe: a multinational, multicentre cohort study. The Lancet Child \& Adolescent Health, 4(9), 653-661.

Guo, Y. R, Cao, Q. D, Hong, Z. S, Tan, Y. Y, Chen, S. D, Jin, H. J, \& Yan, Y (2020). The origin, transmission and clinical therapies on coronavirus disease 2019 (COVID-19) outbreak-an update on the status. Military Medical Research, 7(1), 1-10.

Hedrich, C. M (2020). COVID-19-Considerations for the paediatric rheumatologist. Clinical Immunology, 214, 108420.

Ho, C. L. T, Oligbu, P, Ojubolamo, O, Pervaiz, M, \& Oligbu, G (2020). Clinical characteristics of children with COVID-19. AIMS public health; 7(2), 258.

Hoang, A, Chorath, K, Moreira, A, Evans, M, Burmeister-Morton, F, Burmeister, F, \& Moreira, A (2020). COVID-19 in 7780 pediatric patients: a systematic review. EClinicalMedicine, 24, 100433.

Ji, L. N, Chao, S, Wang, Y. J, Li, X. J, Mu, X. D, Lin, M. G, \& Jiang, R. M (2020). Clinical features of pediatric patients with COVID-19: a report of two family cluster cases. World Journal of Pediatrics, 1 .

Lan, L, Xu, D, Xia, C, Wang, S, Yu, M, \& Xu, H (2020). Early CT findings of coronavirus disease 2019 (COVID-19) in asymptomatic children: a singlecenter experience. Korean journal of radiology, 21(7), 919.

Loney, P. L, Chambers, L. W, Bennett, K. J, Roberts, J. G, \& Stratford, P. W (1998). Critical appraisal of the health research literature: prevalence or incidence of a health problem. Chronic Dis Can, 19(4), 170-6.

Lou, M. X X, Shi, C. X, Zhou, C. C, \& Tian, M. Y. S (2020). Three children who recovered from novel coronavirus 2019 pneumonia. Journal of paediatrics and child health.

Ludvigsson, J. F (2020). Systematic review of COVID-19 in children shows milder cases and a better prognosis than adults. Acta paediatrica, 109(6), 10881095 .

Ma, X, Su, L, Zhang, Y, Zhang, X, Gai, Z, \& Zhang, Z (2020). Do children need a longer time to shed SARS-CoV-2 in stool than adults?. Journal of Microbiology, Immunology and Infection, 53(3), 373-376.

McAbee, G. N, Brosgol, Y, Pavlakis, S, Agha, R, \& Gaffoor, M (2020). Encephalitis associated with COVID-19 infection in an 11-year-old child. Pediatric neurology, 109, 94 .

Mehta, N. S, Mytton, O. T, Mullins, E. W, Fowler, T. A, Falconer, C L, Murphy, O. B, \& Nguyen-Van-Tam, JS (2020). SARS-CoV-2 (COVID-19): what do we know about children? A systematic review. Clinical Infectious Diseases, 71(9), 2469-2479.

Miot, H. A (2016). Agreement analysis in clinical and experimental trials.

Moher, D, Shamseer, L, Clarke, M, Ghersi, D, Liberati, A, Petticrew, M, \& Stewart, LA (2015). Preferred reporting items for systematic review and metaanalysis protocols (PRISMA-P) 2015 statement. Systematic reviews, 4(1), 1-9.

Moola, S, Munn, Z, Sears, K, Sfetcu, R, Currie, M, Lisy, K, \& Mu, P (2015). Conducting systematic reviews of association (etiology): the Joanna Briggs Institute's approach. JBI Evidence Implementation, 13(3), 163-169.

Nunes, M D. R, Pacheco, S. T D A, Costa, C I. A, Silva, J. A. D, Xavier, W. D. S, Victória, JZ (2020). Diagnostic tests and clinical characteristics of covid-19 in children: an integrative review. Texto Contexto-Enfermagem; 29.

Oliveira, V. M. M, de Almeida-Neto, P. F, Damasceno de Lima, F. D. P, de Sousa, S. K. F, de Sousa, A. C, Galdino, R. S, de Matos, D. G, Cabral, B. G. A. T, \& Lima, G. P (2021). OVID 19-How is the Exposure of the Pediatric Population? A Systematic Review Protocol. American Journal of Infectious Diseases, 17 (2), 49-54.

Ouzzani, M, Hammady, H, Fedorowicz, Z, \& Elmagarmid, A (2016). Rayyan-a web and mobile app for systematic reviews. Systematic reviews, 5(1), 1-10. 
Oxman, A. D, \& Guyatt, G. H (1991). Validation of an index of the quality of review articles. Journal of clinical epidemiology, 44(11), 1271-1278.

Park, J. Y, Han, M. S, Park, K. U, Kim, J. Y, \& Choi, E. H (2020). First pediatric case of coronavirus disease 2019 in Korea. Journal of Korean medical science, 35(11).

Qiu H, Wu, J, Hong, L, Luo, Y, Song, Q, Chen, D (2020). Clinical and epidemiological features of 36 children with coronavirus disease 2019 (COVID-19) in Zhejiang, China: an observational cohort study. Lancet Infect dis; 20(6), 689-696.

Rombey, T, Doni, K, Hoffmann, F, Pieper, D, \& Allers, K (2020). More systematic reviews were registered in PROSPERO each year, but few records' status was up-to-date. Journal of clinical epidemiology, 117, 60-67.

Shang, F. N, Huang, Y. D, Lu, J. M, Zhu, Y. Q, Zhu, L, Li, Z. P, Xu, H (2020). Clinical Pharmaceutical Care and Interpretation of Children with COVID-19. Chin pharm j. 55(10).

Shen, K L, Yang, Y. H, Jiang, R. M, Wang, T. Y, Zhao, D. C, Jiang, Y, \& Wang, X. F (2020). Updated diagnosis, treatment and prevention of COVID-19 in children: experts' consensus statement (condensed version of the second edition). World Journal of Pediatrics, 16(3), $232-239$.

Shen, Q, Guo, W, Guo, T, Li, J, He, W, Ni, S, \& Peng, H. (2020). Novel coronavirus infection in children outside of Wuhan, China. Pediatric pulmonology, 55(6), 1424-1429.

Su, L, Ma, X, Yu, H, Zhang, Z, Bian, P, Han, Y, \& Gai, Z (2020). The different clinical characteristics of corona virus disease cases between children and their families in China-the character of children with COVID-19. Emerging microbes \& infections, 9(1), 707-713.

Tian, Y, Rong, L, Nian, W, \& He, Y (2020). Review article: gastrointestinal features in COVID-19 and the possibility of faucal transmission Aliment Pharmacol Ther 51: 843-851. Published online.

Tufanaru, C, Munn, Z, Aromataris, E, Campbell, J, \& Hopp, L (2017). Systematic reviews of effectiveness. Joanna Briggs Institute reviewer's manual, 3.

Wang, E, \& Brar, K (2020). COVID-19 in children: an epidemiology study from China. The Journal of Allergy and Clinical Immunology. in Practice, 8(6), 2118

World Health Organization (2020). Coronavirus disease 2019 (COVID-19): situation report. WHO.

Xing, Y. H, Ni, W, Wu, Q, Li, WJ, Li, GJ, Wang, W. D, \& Xing, Q. S (2020). Prolonged viral shedding in feces of pediatric patients with coronavirus disease 2019, Journal of Microbiology. Immunology and Infection, 25.

Zhang, T, Cui, X, Zhao, X, Wang, J, Zheng, J, Zheng, G, \& Xu, Y (2020). Detectable SARS-CoV-2 viral RNA in feces of three children during recovery period of COVID-19 pneumonia. Journal of medical virology, 92(7), 909-914.

Zhou, P, Yang, X. L, Wang, X. G, Hu, B, Zhang, L, Zhang, W, \& Chen, H. D (2020). A pneumonia outbreak associated with a new coronavirus of probable bat origin. Nature. 579 (7798), 270-273.

Zhu, L, Wang, J, Huang, R, Liu, L, Zhao, H, Wu, C, \& Zhu, C (2020). Clinical characteristics of a case series of children with coronavirus disease 2019. Pediatric pulmonology, 55(6), 1430-1432. 